\title{
Atitudes de liderança entre professores
}

\section{Leadership behavior among professors}

\author{
Luiz Fernando Quintanilha
}

Autor para correspondência. Universidade Salvador, Centro Universitário FTC. Salvador, Bahia, Brasil. ORCID: 0000-0001-8911-9806. quintanilha.If@gmail.com

RESUMO | INTRODUÇÃO: Liderança é um conceito primariamente desenvolvido na área de administração, porém tem sido incorporado de forma mais profunda na educação. Ações de liderança são cada vez mais requisitadas em espaços educacionais a fim de conduzi-los aos objetivos institucionais. Entretanto, existem fatores que afastam os educadores da apropriação desses conceitos teóricos tais como demandas variadas, falta de tempo e incentivos financeiro e profissional. Desta forma, pode ocorrer um distanciamento da eficácia em suas atitudes e um prejuízo no desenvolvimento da instituição de ensino. OBJETIVO: O presente trabalho se propôs a investigar quais atitudes atribuídas a líderes são mais vivenciadas por professores. MÉTODOS: Estudo transversal, com 20 professores de ensino médio e superior de instituições públicas e privadas. Foi aplicado um questionário estruturado "Inventário de habilidades e atitudes de liderança", através do aplicativo Google Forms, contendo 27 asserções relatando atitudes positivas de liderança e utilizando a escala de Likert de 1 a 5 para cada resposta. RESULTADOS: Entre as atitudes com que os professores entrevistados mais concordavam e realizavam estavam "demonstra entusiasmo e gosto pelo seu trabalho" e "valoriza o trabalho da equipe e suas ideias de melhoria". Dentre as menos realizadas, estavam "sente-se à vontade diante de imprevistos e situações difíceis" e "assume responsabilidade pelo trabalho de todos os participantes do seu espaço educacional". CONCLUSÃO: Educadores têm pontos a serem aprimorados em relação a suas atitudes de liderança e o incentivo à formação desses profissionais se torna importante ao contribuir para a melhoria da educação nacional.

\begin{abstract}
INTRODUCTION: Leadership is an established well concept in administration area, but it has been introduced more deeply in education. Leadership actions are increasingly required in educational spaces in order to lead them to institutional goals. However, some factors keep educators away from these theoretical concepts such as varied demands, lack of time and financial and professional incentives. Moreover, there may be a decreased of effectiveness in their behaviors and a developmental impairment of the education institution. OBJECTIVE: This study's aim was to investigate which leadership behaviors are most performed by professors. METHODS: It was carried out a cross-sectional study of 20 professors from public and private institutions. A structured questionnaire "Leadership Skills and Behaviors Inventory" was applied through Google Forms application, including 27 statements reporting positive leadership behaviors and using Likert Scale from 1 to 5 for each answer. RESULTS: The most agreed and performed behaviors of interviewed professors were "shows enthusiasm and liking to their work" and "values the team's work and its ideas for improvement". The least accomplished were "feel comfortable in face of unexpected events and difficult situations" and "take responsibility for all participants' work in their educational space". CONCLUSION: Educators have points to be improved in relation to their leadership behaviors. Furthermore encouraging these professionals training becomes important to improve national education.
\end{abstract}

KEYWORDS: Leadership. Education. Teaching.

PALAVRAS-CHAVE: Liderança. Educação. Ensino. 


\section{Introdução}

As instituições de ensino estão inseridas em um mundo de relações cada vez mais complexas, sofrem pressões das mudanças socioculturais e exercem função preponderante na transformação social. Por este motivo, os atores dessas instituições, em especial o corpo docente, têm papel decisivo nas atribuições desses espaços e no atingimento dos objetivos definidos pelos regimentos internos e externos. Para tal, é necessário que os colaboradores exerçam papéis de gestão e liderança, o que muitas vezes não é realizado de maneira adequada por indivíduos devidamente capacitados, trazendo consequências negativas para as instituições e todos os envolvidos no processo educacional.

O conceito de liderança tem evoluído muito e sofre constantes transformações. Para Bennis", "liderança é o que dá a uma organização sua visão e capacidade para transformar essa visão em realidade". Já para Robbins², "liderança é a capacidade de influenciar um grupo em direção ao alcance dos objetivos". Segundo Chiavenato ${ }^{3}$, "liderança é condição necessária em todos os tipos de organização humana, ou seja, para a obtenção de qualquer resultado desejado pela empresa é necessário conhecer a natureza humana e saber conduzir as pessoas". Apesar das diversas definições, há similaridades entre alguns conceitos, especificamente quando englobam a noção de que alguns atributos dos líderes fazem com que eles se destaquem frente a algumas situações específicas e quando apontam a liderança como uma função capaz de lidar, motivar e alcançar o melhor de pessoas.

Os estudos sobre liderança são mais abordados na área da administração, porém a pedagogia se apropriou de vários conceitos já que, em espaços educacionais, as ações de liderança são fundamentais para o bom funcionamento deles. Ações isoladas de líderes sem o devido embasamento teórico podem não ser tão eficazes como eles imaginam, por maior que seja a experiência do profissional e a sua boa vontade. Por este motivo, apropriar-se dos conceitos teóricos acerca da liderança é um passo importante para a gestão educacional.

Algumas teorias são bastante disseminadas, por exemplo, a teoria dos traços de personalidade e dos estilos de liderança ${ }^{4,5}$. Segundo a teoria de traços de personalidade, os líderes apresentam características físicas, sociais e intelectuais tais como autoconfiança, motivação, habilidades de comunicação que os farão líderes natos, ou seja, trata-se de uma teoria que versa sobre ter ou não ter a capacidade de liderar. Tal teoria é bastante debatida, pois muitos discordam de que alguém nasce para ser líder enquanto outros nascem para ser liderados ${ }^{6}$. Uma outra teoria é a de estilos de liderança que, em geral, são divididas em autocrática e democrática ${ }^{7}$. A democrática versa sobre a distribuição de poder e se sustenta no fato de que cada indivíduo pode exercer a liderança em determinada área ${ }^{8}$. Ela é amplamente aceita e, inclusive, é citada na Constituição Federal de 1988 e nas Leis e Diretrizes e Bases da Educação (LDB). Supõe-se, portanto, que em instituições de ensino brasileiras, a gestão deve ser realizada de forma democrática respeitando a individualidade e a coletividade a fim de alcançar os objetivos propostos, ultimamente a qualidade do processo de aprendizagem.

O que se observa, porém, devido a fatores dos mais diversos, é que os agentes transformadores dessas instituições muitas vezes têm dificuldade em exercer certas atitudes que são consideradas positivas na gestão educacional. Frente ao exposto, o presente trabalho investigou quais dessas atitudes de liderança são executadas mais facilmente e quais são menos executadas por profissionais da área educacional. Além disso, esse estudo se propõe a discutir os porquês da execução apropriação ou não das mesmas.

\section{Desenvolvimento}

Trata-se de um estudo transversal, descritivo, que avaliou as percepções de professores de ensino médio e superior de instituições públicas e privadas quanto à apropriação de atitudes atribuídas a líderes. Foi aplicado o questionário "Inventário de habilidades e atitudes de liderança" proposto por Luck, com adaptações ${ }^{4}$. Foi utilizado o aplicativo Google Forms para a aplicação do inventário online. Foram apresentadas aos entrevistados 27 assertivas que relatavam atitudes positivas de liderança e foi usada a escala de Likert de 1 a 5 (onde 1 significava discordo plenamente e 5 significava concordo plenamente) para cada uma dessas asserções.

Ao final, foi utilizado o programa Excel 2016 para avaliar o padrão de respostas descritas quanto à execução, ou não, de tais atitudes entre os respondentes. 
Gráficos de radar foram elaborados para demonstrar o padrão de respostas entre os entrevistados, considerando as atitudes mais e menos realizadas/aplicadas.

Foram coletados 20 questionários completos e os padrões de respostas revelaram algumas atitudes mais facilmente executadas pelos respondentes e outras menos. Entre as atitudes com que os professores mais concordavam e realizavam estavam as seguintes: "demonstra entusiasmo e gosto pelo seu trabalho" e "valoriza o trabalho da equipe e suas ideias de melhoria" (Figura 1).

Figura 1. Atitudes de liderança mais executadas por professores

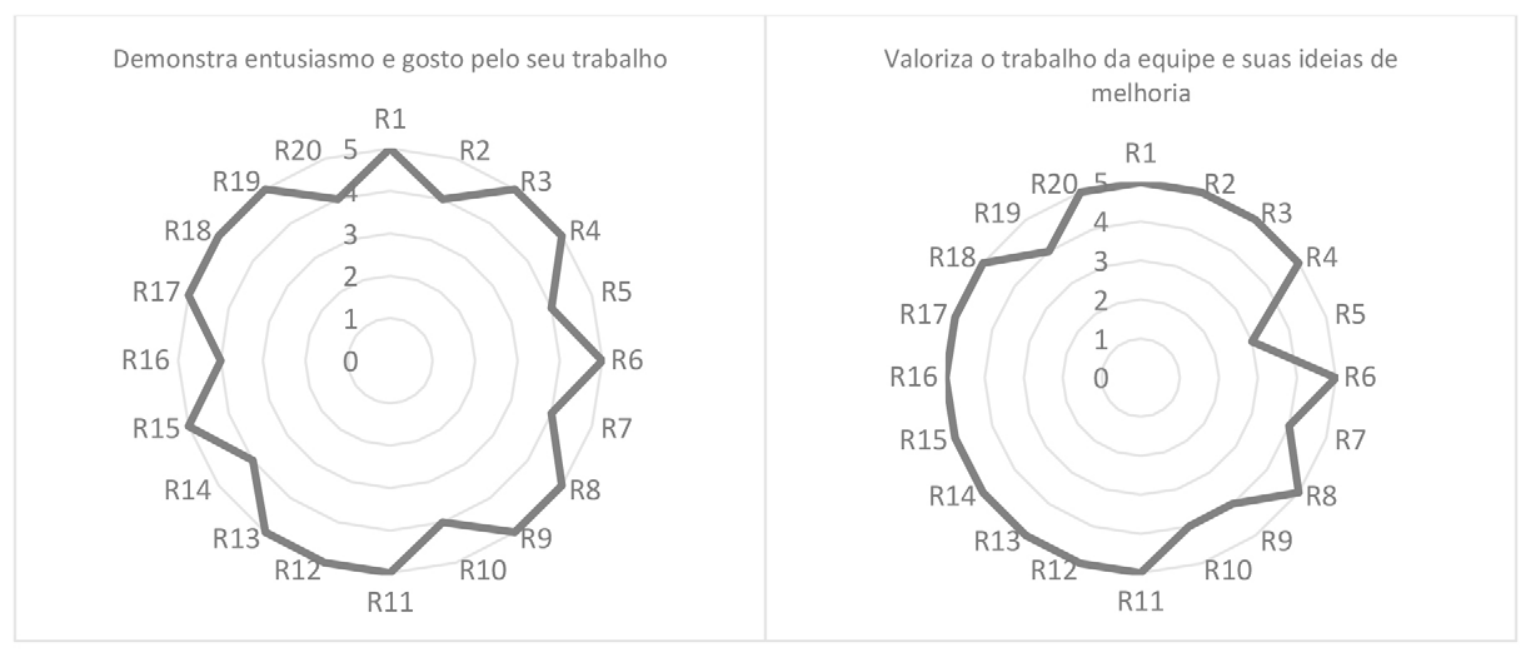

Dentre tais atitudes, algumas eram esperadas figurar entre as de maior aceitação pela própria característica do trabalho docente. Em geral, educadores são entusiastas com seu trabalho devido a importância social que eles têm. Além disso, a valorização do trabalho em equipe e de suas ideias de melhoria remetem a teoria da liderança democrática, na qual as decisões para alcançar os objetivos traçados são discutidas coletivamente para melhor embasamento e construção das melhores estratégias.

Por outro lado, as atitudes de maior discordância entre os grupos de professores avaliados foram: "sente-se a vontade diante de imprevistos e situações difíceis" e "assume responsabilidade pelo trabalho de todos os participantes do seu espaço educacional" (Figura 2). 
Assume responsabilidade pelo trabalho de todos os participantes do seu espaço educacional

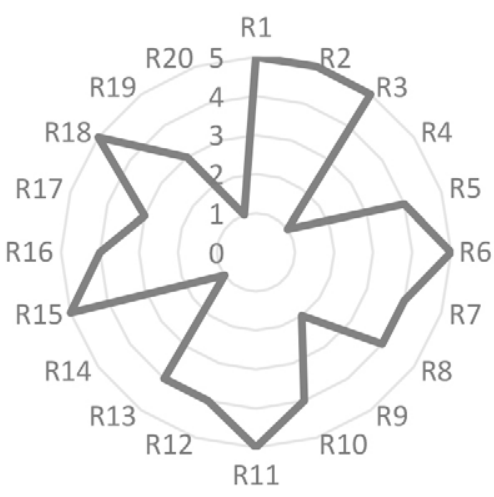

Sente-se a vontade diante de imprevistos e situações difíceis

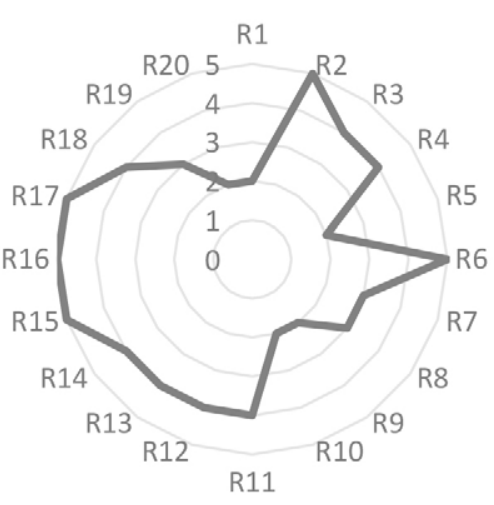

Ao avaliar a dificuldade em encarar situações difíceis e imprevistos, evidenciou-se uma característica pessoal geralmente atribuída a líderes natos: a autoconfiança. Esta característica é exatamente aquela que faz com o que o indivíduo que exerce função de liderança receba uma dificuldade ou imprevisto e se convença de que ele é capaz de solucioná-lo e o encara como mais um desafio e oportunidade de aprendizado. Tal característica, que segundo a teoria dos traços de personalidade é inata de grandes líderes, pode ser desenvolvida com várias estratégias de aperfeiçoamento profissional que geralmente os docentes não têm acesso ou oportunidades. Além disso, alguns autores criticam a forma com que a liderança é abordada em instituições de ensino e ainda investigam as melhores formas de fazê-lo, o que dificulta ainda mais esse crescimento ${ }^{9,10,11}$.

Finalmente, em uma sociedade que tende a individualidade, é extremamente comum que cada um "olhe o seu lado", fazendo o seu trabalho sem se preocupar com o trabalho desenvolvido pelos seus colegas. Isso é extremamente danoso para uma instituição de ensino dada a necessidade de uma construção coletiva para o desenvolvimento de melhores práticas pedagógicas.

Todavia, apesar dos aspectos supracitados e da falta de conhecimento da maioria, a tendência das respostas apontada pela escala Likert foi, em geral, muito positiva, evidenciando que esses indivíduos, por exercerem nos seus cotidianos atividades ligadas a educação, demonstram executar atividades consideradas positivas de liderança, mesmo sem o devido embasamento teórico (Tabela 1). É possível que o aprendizado prático, agregado às características pessoais, proporcione a esses indivíduos a execução de ações positivas de liderança de maneira inconsciente. 
Tabela 1. Atitudes de liderança e suas respectivas pontuações, em média, através da escala Likert

\begin{tabular}{|c|c|}
\hline Atitudes & Média Respostas \\
\hline Valoriza o trabalho da equipe e suas ideias de melhoria. & 4.70 \\
\hline Demonstra entusiasmo e gosto pelo seu trabalho. & 4.65 \\
\hline Demonstra gostar de trabalhar com pessoas. & 4.60 \\
\hline $\begin{array}{l}\text { Atua de forma comprometida e determinada em relação ao cumprimento dos objetivos } \\
\text { estabelecidos. }\end{array}$ & 4.60 \\
\hline $\begin{array}{l}\text { Equilibra as interfaces e diferentes áreas de ação do seu espaço educacional e a interação } \\
\text { entre as pessoas. }\end{array}$ & 4.50 \\
\hline Lida com conflitos e tensões com naturalidade e discernimento, sem dramatizações. & 4.50 \\
\hline $\begin{array}{l}\text { Atua a partir de visão abrangente do trabalho educacional, do papel da instituição de } \\
\text { ensino e dos processos de aprendizagem. }\end{array}$ & 4.45 \\
\hline $\begin{array}{l}\text { Promove a definição da visão e da missão do seu espaço educacional e os torna um } \\
\text { modo de pensar vivo e orientador das práticas educacionais. }\end{array}$ & 4.40 \\
\hline $\begin{array}{l}\text { Mantem um bom relacionamento interpessoal com todas as pessoas da sua instituição } \\
\text { de ensino. }\end{array}$ & 4.40 \\
\hline Mantém o bom humor próprio e da equipe & 4.40 \\
\hline Presta contínua atenção à dimensão social do ambiente educacional. & 4.40 \\
\hline Reconhece o impacto do seu comportamento sobre o das demais pessoas. & 4.35 \\
\hline Constrói clima de confiança na sua instituição orientado por elevadas expectativas. & 4.35 \\
\hline $\begin{array}{l}\text { Demonstra interesse genuíno pelo trabalho dos professores, dos funcionários e dos } \\
\text { alunos. }\end{array}$ & 4.30 \\
\hline Demonstra autoconfiança em suas ações. & 4.30 \\
\hline Demonstra comprometimento com resultados de sua instituição (todos os setores). & 4.30 \\
\hline Comunica-se claramente procurando perceber como é recebido e entendido. & 4.30 \\
\hline Persevera diante de problemas e dificuldades os assumindo como desafios. & 4.30 \\
\hline Compartilha o processo de tomada de decisões. & 4.26 \\
\hline $\begin{array}{l}\text { Estimula canais de comunicação positivos entre todos os membros das comunidades } \\
\text { educacionais. }\end{array}$ & 4.25 \\
\hline Estabelece condições para a melhoria do trabalho de sua instituição como um todo. & 4.25 \\
\hline Estabelece elos significativos de atuação entre professores, funcionários e alunos. & 4.25 \\
\hline Desenvolve em sua instituição um ambiente de aprendizagem em comunidade. & 4.20 \\
\hline $\begin{array}{l}\text { Estimula participantes de todos os segmentos da instituição a se envolverem na } \\
\text { realização dos projetos como uma causa de todos. }\end{array}$ & 4.20 \\
\hline Orienta-se por elevadas expectativas em relação ao próprio trabalho e ao dos demais. & 4.20 \\
\hline $\begin{array}{l}\text { Assume responsabilidade pelo trabalho de todos os participantes do seu espaço } \\
\text { educacional. }\end{array}$ & 3.70 \\
\hline Sente-se a vontade diante de imprevistos e situações difíceis. & 3.60 \\
\hline
\end{tabular}

Finalmente, este trabalho aponta para a necessidade de desenvolver e aprimorar habilidades de liderança nos profissionais educadores, por mais experientes que eles possam ser. Admitir, como qualquer ser humano, a incompletude de seus conhecimentos e atitudes - neste caso as de liderança em espaços educacionais - pode ser um elemento estimulador fundamental da aquisição de novos conhecimentos e desenvolvimento profissional.

\section{Considerações Finais}

Os presentes resultados sinalizam para o fato de que, caso se apropriassem do conjunto de ideias norteadoras da liderança, os educadores aqui avaliados poderiam trabalhar ainda melhor executando ações que alavancariam seus espaços educacionais e, ainda, poderiam utilizar tais conhecimentos e replicá-los entre seus pares. 


\section{Conflitos de interesses}

Nenhum conflito financeiro, legal ou político envolvendo terceiros (governo, empresas e fundações privadas, etc.) foi declarado para nenhum aspecto do trabalho submetido (incluindo mas não limitando-se a subvenções e financiamentos, participação em conselho consultivo, desenho de estudo, preparação de manuscrito, análise estatística, etc.).

\section{Referências}

1. Bennis W. The leadership advantage. Leader to Leader; 1999.

2. Robbins S. Administração em gestão escolar. Sao Paulo: Saraiva; 2000.

3. Chiavenatto I. Introdução a teoria geral da administração. Rio de Janeiro: Campu; 2000.

4. Luck H. Liderança em gestão escolar. Petropolis: Vozes; 2014.

5. Brungardti, C. The Making of Leaders: A Review of the Research in Leadership Development and Education. Journal of leadership and organizational studies;1996;3 (3):81-95. doi: $\underline{10.1177 / 107179199700300309}$

6. Vergara SC, A liderança aprendida. 2007;6(1):61-65. doi: 10.12660/gvexec.v6n1.2007.34329

7. Santos GF, Assunção JJO. Estilos de liderança: enfoque na teoria x e teoria y de Douglas McGregor. Universitari@. 2010;1(2):1-14.

8. Araujo LCG, Garcia AA. Gestão de Pessoas. São Paulo: Atlas; 2010.

9. Rost JC, Barker RA. Leadership Education in Colleges: Toward a 21st Century Paradigm. Jornal of leadership and organizational studies. 2000;7(1):3-12. doi: 10.1177/107179190000700102

10. Ricketts JC, Rudd RD. A Comprehensive Leadership Education Model To Train, Teach, and Develop Leadership in Youth. Journal of Career and Technical Education. 2002;19(1):7-17.

11. Elmuti D, Minnis W, Abebe M. Does education have a role in developing leadership skills? Management Decision. 2005;43(78):1018-1031. doi: $10.1108 / 00251740510610017$ 